\title{
ESTUDO TEÓRICO DAS INTERAÇÕES ENTRE ISONIAZIDA E NADH E A ENZIMA INHA, ENOIL-ACP REDUTASE DO MYCOBACTERIUM TUBERCULOSIS.
}

\author{
$\underline{\text { J. R. C. BAHIA }}{ }^{1,2}$, F. J. N. FERREIRA ${ }^{1,2}$, e A. S. CARNEIRO ${ }^{1,2}$ \\ ${ }^{1}$ Laboratório Computacional de Sistemas Biológicos - Universidade Federal do Pará. \\ ${ }^{2}$ Programa de Pós-Graduação em Química Medicinal e Modelagem Molecular-ICS/UFPA . \\ E-mail para contato: jeann_ricardo@hotmail.com
}

RESUMO - Objetivo deste trabalho foi avaliar as principais interações entre os ligantes NADH e Isoniazida e a enzima InhA. Essa avaliação foi realizada através do método de simulação de Dinâmica Molecular com o pacote de programas do AMBER14,coma estruturas obtidas através do PDB 4TRO. Ao avaliar a trajetória foi possivel perceber as principais interações que conferem o efeito farmacológico a isoniazida frente a InhA, a principal foi o empilhamento de cargas entre a PHE149 e a porção isonicotinoil da Isoniazida. Esta interação inclusive demonstrou um padrão energético favorável a interação, -2,874 $\mathrm{kcal} / \mathrm{mol}$, a qual não foi visualizada no sistema contendo NADH e InhA. Este trabalho ajuda na compreensão de quais interações provocam a inibição da InhA e consequente morte do bacilo da Tuberculose.

Palavras-chave: Isoniazida, tuberculose, química computacional.

\begin{abstract}
The objective of this work was to evaluate the main interactions between NADH and Isoniazid ligands and the enzyme InhA. This evaluation was performed through the Molecular Dynamics simulation method with the AMBER14 program package, as structures obtained through the 4TRO PDB. When evaluating the trajectory, it was possible to understand the main interactions that confer the pharmacological effect of isoniazid against InhA, the main one being the stacking of charges between PHE149 and the isonicotinoyl portion of Isoniazid. This interaction even showed an energetic interaction pattern, $-2.874 \mathrm{kcal} / \mathrm{mol}$, which was not visualized in the system containing $N A D H$ and InhA. This work helps in understanding which interactions provoke the inhibition of InhA and consequent death of the Tuberculosis bacillus.
\end{abstract}

Keywords: Isoniazid, tuberculosis, computational chemistry, molecular dynamics. 


\section{INTRODUÇÃO}

INOVAÇÃO TERAPEUUTICA

A Isoniazida é o profármaco sintético mais antigo, barato e efetivo da primeira linha de tratamento da Tuberculose. Ela deve ser ativada pela catalase-peroxidase do Mycobacterium tuberculosis, KatG, que produz um aduto isonicotinoil-NADH, INNADH, o qual se dirige a proteína Enoil-ACP redutase do M. tuberculosis, InhA, a fim de interromper a cadeia de síntese de ácidos micólicos da parede celular micobacteriana. A resistência a isoniazida tem origem em mutações em alguns genes, os principais são kat $\mathrm{G}$ e $i n h \mathrm{~A}$, e é uma das formas mais comuns de tuberculose resistente e representa uma ameaça ao controle dessa doença. $\mathrm{O}$ desenho de fármacos que não necessitem de ativação por outras enzimas como a KatG é promissor para o desenvolvimento de fármacos mais efetivos contra o M. tuberculosis. Sendo assim, o presente estudo visa a avaliação das interações que conferem a ação farmacológica a isoniazida frente a InhA e comparar ao do cofator natural da InhA, NADH.

\section{MATERIAIS E MÉTODOS}

O sistema utilizado neste trabalho, proteína (InhA) - ligante (Isoniazida e NADH), foi captado a partir do banco de dados PDB (em inglês, Protein Data Bank), cujo código é 4TRO (CHOLLET et al., 2015). O método para obtenção de cargas dos ligantes foi Hartree-Fock (HF), com funções de base 6-31 $\mathrm{g}^{*}$. Como o sistema a ser simulado é biológico, deve-se mimetizar esse ambiente. Para isso é adicionado contra íons o quanto necessário para neutralizar as cargas do complexo. Em seguida é adicionada uma caixa de água (TIP3PBOX) octaédrica com $10 \AA \AA$ de aresta.

Após foram realizadas as etapas de minimização em três passos, relaxar os hidrogênios, depois a água e por último o sistema inteiro. Após foi realizado o aquecimento do sistema para $300 \mathrm{~K}$ realizados em 5 etapas de $50 \mathrm{em} 50 \mathrm{~K}$, a partir de $50 \mathrm{~K}$. Feito isto passa-se a etapa de equilíbrio do sistema biológico para só depois iniciar a simulação de dinâmica molecular propriamente dita. A simulação foi realizada em 100ns, com o intervalo de 5 em $5 \mathrm{~ns}$ (5 000 000 de passos). Após foi avaliada a trajetória usando o RMSD (Root Mean Square Deviation) e realizado o cálculo de energia livre do sistema pelo método do MM/GBSA usando o protocolo de decomposição padrão no AMBER 14 (CASE et al., 2014).

\section{RESULTADOS E DISCUSSÃO}

Foi usado o frame 8500 (85ns) para analise estrutural da dinâmica no software VMD cujo é capaz de mostrar as distâncias entre os átomos compostos químicos. Logo, pode-se verificar as distâncias das ligações de hidrogênio (LH) que os átomos envolvidos nas interações realizam conforme ilustrado na Figura . Naquele momento da trajetória os resíduos

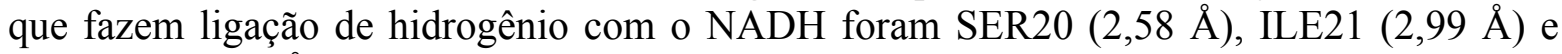
THR196 (3,05 Å) na porção pirofosfato do NADH, nesta mesma porção da Isoniazida

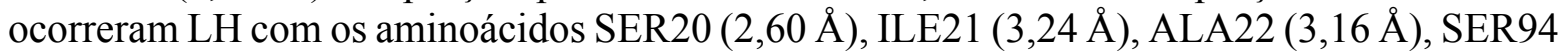
$(2,57 \AA)$; na região Ribose de Nicotinamida (RN) do NADH a LYS165 (2,89 $\AA)$, ALA191

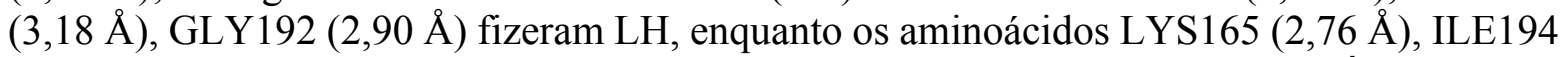
$(3,05 \AA)$, THR196 (2,59 ̊̊) fizeram LH com a mesma região da isoniazida. É importante destacar que é nesta região da isoniazida ocorre a principal interação que confere sua propriedade bactericida, o empilhamento de carga $\pi$ entre o isonicotinoil e a PHE149 
(CHOLLET et al., 2015; ROZWARSKI, 1998); na região Ribose de Adenina (AR) a LH do NADH foi feita pela GLY96 (3,12 $\AA$ ), e na região AR da isoniazida foi feita pela VAL65 $(3,18 \AA)$ e GLY96 (2,85 A). Ainda nessa porção, o empilhamento de cargas $\pi$ no NADH e isoniazida foi realizado pelas PHE41 e PHE97 (Figura ). Esse achado corrobora com resultados de cristalografia de outros trabalhos (CHOLLET et al., 2015; DIAS et al., 2007; ROZWARSKI, 1998; SCHROEDER et al., 2005).

Figura - Visualização das principais interações entre os resíduos do sitio ativo da InhA e NADH (A) e Isoniazida (B). A linha dupla tracejada da imagem representa o empilhamento de cargas $\pi$ face-a-face deslocada. As linhas simples tracejadas representam as Ligações de Hidrogênio (LH). Os valores destacados se referem a distância em Å (Angstrons) entre os átomos da LH.

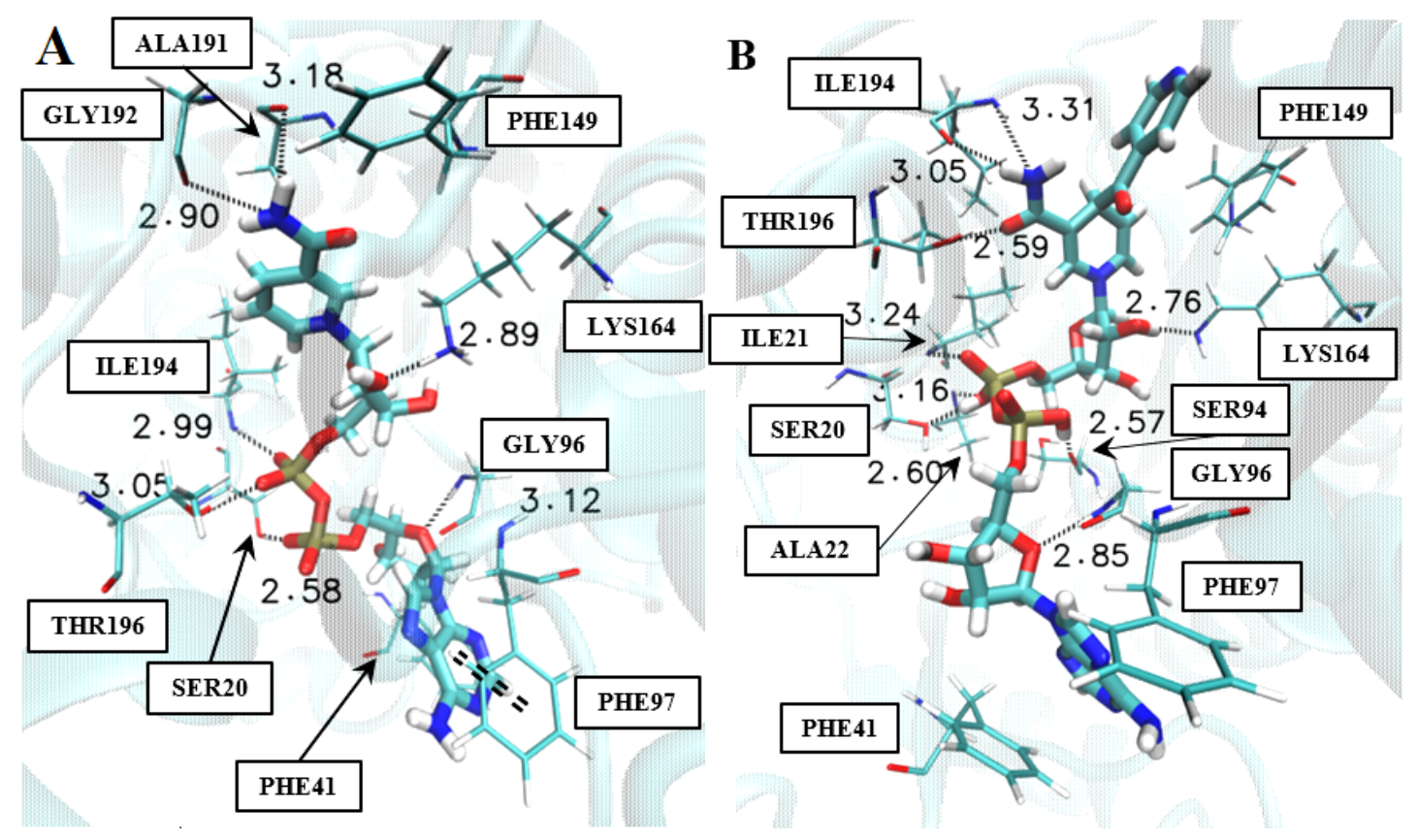

Ao compararmos as energias fica evidente que o sistema com o inibidor Isoniazida ($72,038 \mathrm{kcal} / \mathrm{mol}$ ) é o que apresenta menor valor de energia, portanto o sistema é o mais espontâneo que o cofator natural da InhA, NADH (-41,463 kcal/mol).

\section{CONCLUSÃO}

Este trabalho foi possível avaliar as interações que dão a isoniazida seu efeito farmacológico. O empilhamento de carga foi observado na isoniazida ao contrário do que ocorreu com o NADH. Quanto a energia total do sistema com a isoniazida se mostrou mais espontâneo que o NADH. Através do entendimento das principais interações que a isoniazida faz é possível planejar um fármaco com o perfil de interação semelhante, que possa compor a multidrogaterapia da tuberculose. 


\section{REFERÊNCIAS}

INOVAÇÃO TERAPEUUTICA

CHOLLET, A. et al. Crystal structure of the enoyl-ACP reductase of Mycobacterium tuberculosis (InhA) in the apo-form and in complex with the active metabolite of isoniazid pre-formed by a biomimetic approach. Journal of Structural Biology, v. 190, n. 3, p. $328-337,2015$.

DIAS, M. V. B. et al. Crystallographic studies on the binding of isonicotinyl-NAD adduct to wild-type and isoniazid resistant 2-trans-enoyl-ACP (CoA) reductase from Mycobacterium tuberculosis. Journal of Structural Biology, v. 159, n. 3, p. 369-380, 2007.

ROZWARSKI, D. A. Modification of the NADH of the Isoniazid Target (InhA) from Mycobacterium tuberculosis. Science, v. 279, n. 5347, p. 98-102, 2 jan. 1998.

SCHROEDER, E. K. et al. Molecular Dynamics Simulation Studies of the Wild-Type, I21V, and I16T Mutants of Isoniazid-Resistant Mycobacterium tuberculosis Enoyl Reductase (InhA) in Complex with NADH: Toward the Understanding of NADH-InhA Different Affinities. Biophysical Journal, v. 89, p. 876-884, 2005.

\section{AGRADECIMENTOS}

Agradecimentos a CAPES pelo fomento e bolsa de pesquisa. Ao Chefe do Laboratório Computacional de Sistemas Biológicos do Instituto de Ciências da Saúde da Universidade Federal do Pará. 